\title{
Capacitação à distância de professores do ensino fundamental no Brasil*
}

\author{
Elba Siqueira de Sá Barreto**
}

\begin{abstract}
RESUMO: O trabalho consiste em reflexão baseada em pesquisa de avaliação externa do programa nacional de capacitação docente transmitido via satélite: "Um salto para o futuro". Reporta-se à pesquisa de campo, abrangendo amostra de telepostos de oito estados das diferentes regiões do país, e examina os pressupostos teóricos-metodológicos e o formato do programa, a interação dos agentes educacionais, o aproveitamento dos cursistas e as condições de implementação. Conclui que o Programa inova quanto à forma e ao conteúdo, podendo vir a constituir importante veículo de atualização de professores do ensino fundamental. Está, contudo, insatisfatoriamente implementado.
\end{abstract}

Palavras-chave: Educação à distância, formação de professores, capacitação em serviço, ensino fundamental, educação e multimeios

As rápidas mudanças provocadas pelas inovações tecnológicas e pela mundialização da economia têm colocado ao nosso tempo desafios que exigem o desenvolvimento do conhecimento em escala até então desconhecida, o que o vem transformando em um dos eixos em torno do qual gravitam as relações da sociedade.

A melhoria da qualidade do ensino básico, mote das políticas públicas na América Latina, conduz a uma estratégia necessária: a da qua-

* Trabalho apresentado no Primeiro Congresso Europeu de Latinoamericanista. Salamanca, Espanha: Instituto de Estudios de Iberoamérica y Portugal — Universidade de Salamanca, 26 a 29 de junho de 1996.

** Pesquisadora da Fundação Carlos Chagas e professora da Faculdade de Educação da USP. 
lificação e requalificação docente. Não mais se trata de formar o professor para transmitir regras e conhecimentos acabados, que permitam a ele e aos alunos situarem-se em um mundo relativamente estável. Uma nova ótica de capacitação emerge, visto que o tempo para a reflexão e a sedimentação do conhecimento torna-se cada vez mais reduzido. Por isso o processo pedagógico tende a privilegiar a aprendizagem e não o ensino, desenvolvendo sobretudo a capacidade de aprender a aprender; tanto o aluno como o professor passam a ter de manejar informações em busca de recíproca complementação; torna-se mais premente a necessidade de cooperação na busca de conhecimento novo; cresce a motivação para a autodidaxia permanente; aumenta a importância do suporte tecnológico para o acesso à informação (Brasil 1994).

Não só os cursos de formação do magistério e as licenciaturas passam a ser colocados sob a mira de uma estratégia mais ampla que resolveu apostar no sistema educacional, como também as propostas de qualificação em serviço assumem um papel privilegiado nessa perspectiva. A capacitação obtida através das formas tradicionais de preparação profissional rapidamente se torna ultrapassada e a exigência de formação continuada transforma-se em desafio. Da mesma maneira que para o conjunto dos profissionais de modo geral, também para os professores o importante será assegurar oportunidades constantes de reciclagem que Ihes permitam manter-se atualizados, tanto do ponto de vista de sua formação geral quanto específica.

Nesse sentido, a análise de um programa de capacitação de docentes em serviço, coordenado pelo Ministério da Educação e Cultura do Brasil (MEC), no desempenho de suas obrigações relativas ao ensino fundamental - quais sejam as de contribuir para compensar as enormes discrepâncias de desempenho encontradas nas escolas das diferentes regiões mantidas pelos estados e municípios - , poderá oferecer subsídios à formulação de políticas mais amplas de qualificação do professor.

\section{Programa Nacional de Capacitação de Docentes à Distância}

"Um salto para o futuro" é um programa de âmbito nacional, transmitido pela televisão via satélite, e destinado à capacitação de professores de primeiras a quartas séries do ensino fundamental, extensível também aos de pré-escola. Tem como parceiros o Ministério 
da Educação (MEC), através da Secretaria Nacional de Educação Básica (Seneb), a Fundação Roquete Pinto, responsável pela Televisão Educativa do Ministério, bem como as Secretarias de Estado da Educação, no que diz respeito às ações de campo. As escolas que oferecem o ensino fundamental e médio pertencem aos sistemas estaduais de ensino, que estão sob a jurisdição dos estados, embora possam ser mantidas por instituições estaduais e municipais, bem como por instituições privadas.

O Programa foi considerado como "o meio mais viável de obter, a curto e médio prazos, uma renovação do sistema educacional", considerando-se que este está predominantemente centrado no desempenho do magistério, o qual se ressente de sérias deficiências de formação. Tem por objetivos: a) levar o professor à formulação de um referencial teórico-metodológico adequado às quatro séries iniciais do $1^{\circ}$ grau e à préescola, focalizando conceitos básicos relativos às disciplinas do núcleo comum do currículo; b) ampliar o nível de conhecimento geral dos professores, acoplando textos com informações atualizadas, veiculadas através de diferentes formas de uso da imagem (Brasil, Fundação Roquete Pinto 1992, p. 1).

Dirige-se a professores em serviço, uma audiência com formação básica em nível de ensino médio. No segundo semestre de 1992 atendeu a 26 unidades federadas, deixando de atingir apenas o estado do Tocantins. Funcionou então através de 556 telepostos, com 16.271 telealunos inscritos.

O programa televisivo possui um segmento ao vivo, é complementado pela utilização de fax e canal de voz e vem apoiado por um texto escrito, o boletim diário. Tem a duração de quatro meses consecutivos, com emissões e discussões nas telessalas durante duas horas diárias. A combinação de vários recursos tecnológicos permite a interatividade, assegurando o constante diálogo entre a equipe de produção e os professores cursistas.

Os dados sintetizados e discutidos neste texto baseiam-se em avaliação externa do Programa, realizada pela Fundação Carlos Chagas, no segundo semestre de 1992 (Barretto 1993). Esse estudo propôs-se a colher informações e a fazer uma apreciação acerca dos seus elementos básicos, a saber: os programas de TV em seu conteúdo, forma e emissão; os materiais impressos de apoio; os agentes educacionais envolvidos; os cursistas; o processo de implementação. 


\section{A metodologia de trabalho}

Tais elementos foram examinados a partir de diferentes focos de análise, que o submeteram ao crivo da análise de profissionais de renomada competência e grande experiência na área, bem como ao teste das dificuldades impostas pela rotina do cotidiano e pelas limitações de caráter político-administrativo. Nesse caso, ao ir além do monitoramento interno do Programa, empenhado em detectar a adequação entre o que foi planejado e o efetivamente realizado, é a eficácia do Programa que está em questão. Trata-se, pois, de uma apreciação fundamentada em critérios de relevância social acerca do valor intrínseco dos objetivos propostos, da pertinência das estratégias escolhidas para alcançá-los, bem como do seu provável impacto nos sistemas de ensino.

O primeiro foco de análise adotado na avaliação do Programa foi o dos especialistas. Estes dedicaram-se ao exame dos aspectos teóricometodológicos e da forma através da qual se consubstanciou a proposta educacional por meio das emissões de televisão e dos boletins diários que as acompanharam. Foram escolhidos entre profissionais que aliavam a experiência no trato das questões relativas à metodologia de ensino e à formação de professores para o ensino básico, ao extenso domínio da área de conhecimento a que foram chamados a opinar.

O segundo foco de análise recaiu sobre os agentes educacionais responsáveis pela execução do Programa. Orientadores de aprendizagem, a cargo de quem ficou o trabalho pedagógico realizado mediante a recepção organizada do Programa, e supervisores, encarregados de prover o apoio pedagógico e administrativo às ações educacionais, foram entrevistados acerca de aspectos fundamentais do trabalho que desenvolviam. Manifestaram-se eles sobre o planejamento das atividades, abordagem metodológica, adequação à clientela, suporte pedagógico, emprego da tecnologia. Foram também entrevistados os coordenadores do Programa nos respectivos estados, os quais prestaram informações relativas às condições gerais de sua implementação e às modalidades de interação entre as diferentes instâncias envolvidas na sua realização.

O terceiro foco de análise incidiu sobre os cursistas, representados por professores e alunos dos cursos de magistério. O modo como eles vivenciaram "Um salto para o futuro", compartilhando expectativas, entusiasmos, dúvidas, dificuldades e experiências, foi em parte abordado mediante a aplicação de um opinionário. Nessa ocasião tiveram opor- 
tunidade de expressar-se a respeito da qualidade, da adequação e da capacidade de comunicação do Programa, dos conteúdos por ele veiculados e da forma como foram transmitidos, das condições em que funcionou o curso, bem como das possibilidades de aplicação em sala de aula. Entrevistas com grupos de telealunos complementaram as informações do opinionário.

Uma das preocupações desse foco de análise também foi a de captar, através da observação das atividades cotidianas na telessala, aspectos da interação dos cursistas com o programa televisivo e com os agentes educacionais. A atenção à dinâmica da telessala contribuiu para melhor interpretar e enriquecer as informações obtidas por meio das declarações dos sujeitos, desvendando facetas ainda não abordadas por outras formas de acompanhamento.

Os telealunos responderam por fim a um questionário que visava aquilatar seu nível de apreensão de conceitos básicos veiculados durante o curso.

O quarto foco de análise destacou o processo de implementação do Programa, ou seja, as condições de funcionamento dos postos receptores, a abrangência territorial, formas variadas de sua utilização, expansão via municípios e faculdades, e alguns indicadores de custos colhidos durante o trabalho de campo.

A análise dos aspectos teórico-metodológicos do Programa, feita pelos especialistas, realizou-se a partir de um roteiro semi-estruturado referente ao trabalho desenvolvido através dos diferentes componentes curriculares e por meio de uma apreciação geral dos aspectos educacionais e técnicos da proposta. As informações provenientes da observação dos telepostos, de opinionários e entrevistas com os agentes educacionais e cursistas, bem como das respostas abertas do questionário dos telealunos, deram, por sua vez, margem à construção de outras tantas categorias de análise. Desse modo foi possível o registro de traços recorrentes, provavelmente indicadores de tendências básicas em relação à concepção e à realização do Programa, e também a consideração de dados singulares significativos.

A pesquisa de campo foi realizada em uma amostra de telecursos que abrangeu oito estados, distribuídos pelas diversas regiões do país: no norte, o Acre; no centro-oeste, Mato Grosso; no nordeste, Ceará, Paraíba e Bahia; no sudeste, Espírito Santo e São Paulo, e, na região sul, Santa Catarina. Em virtude da grande diversidade de situações en- 
contrada nas unidades federadas, das dificuldades de acesso a certos locais de funcionamento dos telepostos, e, sobretudo, da exigüidade do tempo, o trabalho de campo centrou-se nas capitais dos estados. Apenas em Santa Catarina, em São Paulo e no Espírito Santo foram incluídos telepostos no interior, em função do reduzido número deles na capital. No caso do estado de São Paulo, somente o interior veio a constituir a amostra.

Colhida nos diferentes estados, a amostra representou percentuais muito variados da oferta de serviços televisivos aí instalados. Na maior parte dos casos entretanto, pode-se afirmar que os dados são estatisticamente significativos, seja em relação ao número de telessalas observadas, seja em relação à quantidade de cursistas que responderam ao questionário. Os percentuais representados na amostra foram superiores a $10 \%$ em quase todos os estados, o que oferece boa margem de segurança à interpretação dos resultados. Apenas o Ceará, que por condições especiais de implantação, detinha mais da metade das telessalas em funcionamento no país (66\% delas), esteve sub-representado.

Em vista da natureza do estudo - apoiado em instrumentos que demandavam análises predominantemente qualitativas - e das limitações de tempo de que se revestiu o trabalho de campo, o mais seguro é admitir que o exame do material colhido presta-se mais a um levantamento de questões e à sugestão de encaminhamentos, do que a afirmações categóricas ou a generalizações precipitadas acerca das características do Programa e de sua implantação/implementação em âmbito nacional.

\section{A proposta educacional}

O Programa não pretende propriamente dar conta de uma proposta acabada de currículo para as séries iniciais, nem sequer abordar questões relativas aos componentes curriculares de modo exaustivo. Destinado, em princípio, à reciclagem do professor em serviço, não se propõe igualmente a substituir os cursos de formação para o magistério, com vários anos de duração. O que ele procura fazer é organizar o currículo em torno de determinados núcleos conceituais que integram as partes essenciais de determinados conhecimentos de forma mais ampla e menos restritiva do que os conceitos usualmente trabalhados na escola. 
Considerados básicos no início da escolarização regular da criança, os núcleos conceituais são explorados com o professor em seus múltiplos significados nas diferentes disciplinas, propondo-se uma metodologia para trabalhar com eles tendo em vista atualizar a prática docente e contribuir para melhor fundamentá-la.

O modelo subjacente de currículo que informa o programa foge, pois, ao esquema de definição restrita de objetivos de aprendizagem, estreitamente emparelhada com estratégias específicas de ensino para atingi-los. Pode ser entendido antes como um roteiro, que propõe metas de chegada, procura fundamentar os pressupostos de que se vale e sugere alternativas de ação, mas deixa espaço para que o público-alvo o recrie em função da sua própria e diversa realidade. Nesse sentido, as orientações propostas devem ser consideradas como ponto de partida para que o grupo de educadores, em cada local de trabalho, elabore 0 próprio projeto educacional, nele incorporando as experiências compartilhadas com os alunos e com os companheiros de trabalho.

Isso implica que serão selecionados da grade curricular elementos importantes, abordados de modo a deixar claras a integração vertical do currículo, que deve ocorrer ao longo da seriação, e a integração horizontal, que se efetiva através dos conteúdos inter ou transdisciplinares. Pretende-se que a seleção dos conteúdos das áreas e a busca da integração de conhecimentos sejam feitas de modo menos arbitrário do que o usual, a partir da consideração da criança e de seus modos próprios de ser e de aprender como centro do processo educativo (Fundacão Roquete Pinto 1992 - Boletim Especial).

Como uma possibilidade de escolha e não como um modelo fixo a ser seguido indiscriminadamente pelos professores, são propostos quatro núcleos conceituais: tempo, espaço, atividades humanas e linguagens. A intenção é a de trabalhar, através deles, os elementos que compõem uma totalidade de conhecimentos, atendendo à progressiva complexidade dos conceitos no decorrer da escolarização, além de buscar sua integração e melhor explicitação através dos componentes do núcleo comum: português, matemática, ciências, estudos sociais e também da educação artística.

A opção por esses núcleos deve-se ao fato de que comporiam a base dos conhecimentos constituídos pelas crianças, visto que elas tomam consciência de si e do mundo natural e social que as cerca a partir da elaboração dos conceitos de tempo, espaço, das atividades huma- 
nas tais como o brinquedo, o trabalho e a cultura, e, também, através da linguagem. Esta é concebida em seu sentido mais amplo, não apenas como forma de expressão verbal, mas também gestual, plástica, musical, espacial, dramática, utilizada pelos meios de comunicação de massa, pelas artes, pela tecnologia e pela própria ciência (Fundação Roquete Pinto 1992, pp. 2-3 - Boletim Especial).

Assim sendo, ao planejar a programação para um dado período, os profissionais encarregados de produzir os programas das diferentes áreas de estudo deveriam procurar desenvolvê-los focalizando as noções de tempo que lhes eram pertinentes; no período seguinte o mesmo procedimento era utilizado em relação às noções de espaço e assim por diante.

A reflexão mais alentada sobre o papel dos núcleos conceituais no processo de renovação curricular, feita por Bonamino e Brandão com base nos estudos de Bourdieu e de Forquin, aponta para o seu potencial formativo na medida em que contribuiriam para a constituição de habitus escolares. Esses habitus ofereceriam o suporte cognitivo que leva à incorporação, pelos indivíduos, dos esquemas operatórios fundamentais à aprendizagem, o que permitiria tomá-los como ponto de partida para a elaboração de um corpo curricular básico. Assim entendidos, os núcleos conceituais estariam intrinsecamente referenciados na cultura e nas disciplinas do conhecimento, possibilitando a um tempo uma abordagem transcultural e transdisciplinar. Pelo seu caráter abrangente, poderiam, "mais facilmente, oferecer condições de trânsito de um conteúdo a outro, de um campo de conhecimento a outro, de uma matriz disciplinar a outra". Segundo as autoras, essa estratégia estaria sendo considerada pela reflexão mais adiantada na área, como uma das mais eficazes para a qualificação do magistério, pelo seu potencial de ajustar-se à experiência cotidiana da prática escolar, permitindo a colaboração interpares e evitando a segmentação do currículo (Bonamino e Brandão 1995, pp. 21-22).

O tratamento do currículo no Programa foi feito através de uma articulação da exploração dos núcleos conceituais com um enfoque temático, que se mostrou adequada ao desenvolvimento da programação diária de televisão. A escolha dos núcleos conceituais procurou não só quebrar a artificial compartimentalização do conhecimento, como orientar a exploração de cada tema em dada direção, de modo a evitar a mera associação de idéias por ele eventualmente evocadas. A cada dia um tema novo era explorado, intercalando-se a abordagem das áreas curriculares durante a semana. 
O enfoque temático do currículo é também necessariamente integrativo e possibilita uma abordagem interdisciplinar. O desenvolvimento de um tema implica buscar a contribuição das diferentes áreas de conhecimento para esclarecê-lo e aprofundá-lo. Ele permite, por sua vez, partir do vivido, com a riqueza de imagens, de sons e falas, de movimento e emoção que são transmitidos pelo vídeo, para daí passar a um tratamento mais elaborado, mais abstrato do real.

Todavia, nem sempre a adoção do enfoque temático e a utilização da imagem foram suficientes para quebrar a predominância da abordagem expositiva sobre a indutiva, tão arraigada na formação escolar que todos recebemos. A preocupação com a explicação verbal de conceitos está mais presente no Programa do que a tentativa de levar a audiência a chegar a formulá-los a partir do exame do que acontece, de fato, no plano da sala de aula.

A particular concepção de interdisciplinaridade que informa o Programa contribuiu para adensar, do ponto de vista teórico, o tratamento temático adotado, e mostrou-se profícua em relação à sua concepção e à sua formatação. Ela merece, contudo, certos reparos.

A obrigatoriedade de trabalhar o mesmo núcleo conceitual em todas as áreas durante um certo período de tempo pode ter contribuído para produzir ou acentuar um artificialismo, uma relação forçada entre as partes de alguns dos programas diários, que, parece-nos, não pode ser atribuído tão-somente à dificuldade de encontrar material para ilustrar a temática em discussão, de acordo com o formato adotado. Embora possa ter contribuído para estruturar o programa, esse corte transversal determinado pela maneira de trabalhar com os núcleos conceituais pode ter desrespeitado o tempo próprio em que determinado conceito demandava maior aprofundamento na perspectiva de cada área. Uma proposta interdisciplinar não deve implicar a perda da especificidade da abordagem requerida nas diferentes áreas de conhecimento.

Desse modo, a maior flexibilidade no tratamento dos núcleos conceituais ao longo da programação, bem como a abertura para a introdução de outros conceitos básicos, mais afetos a umas disciplinas do que a outras, provavelmente teria propiciado uma integração mais consistente da programação. Foi sintomático que, em sua apreciação, os especialistas, a despeito de, em geral, acharem interessante $o$ tratamento curricular através dos núcleos conceituais, tenham se atido àqueles mais diretamente ligados à abordagem específica da sua própria área. Nes- 
se sentido, procede a pergunta de uma das especialistas em ciências: "Por que não a causalidade como núcleo conceitual?"

A análise da apreensão que os cursistas demonstraram dos conteúdos veiculados pelo Programa indica, por sua vez, que a audiência não chegou a perceber os núcleos conceituais como elementos estruturantes do tratamento dado ao currículo. Ora, se se pretende que a racionália do curso sirva de diretriz para que o professor reprograme suas atividades docentes, o trabalho em torno dos referidos núcleos precisa ganhar maior consistência e receber um tratamento mais explícito ao longo de toda a programação.

Embora essa tentativa de encontrar novos princípios estruturadores para a abordagem curricular tenha se configurado ainda como um esforço preliminar, que merece maior discussão e aprofundamento, do ponto de vista teórico-metodológico a programação reflete, de modo geral, tendências recentes e consolidadas das demais dimensões pedagógicas, bem como das áreas de conhecimento representadas pelos diferentes componentes curriculares. Tendo sido unânime, por parte dos especialistas, uma valoração positiva do Programa, as críticas aos conteúdos e à metodologia por ele veiculados nas suas respectivas áreas foram feitas, via de regra, no sentido de contribuir para o seu aperfeiçoamento. Do mesmo modo, o entusiasmo pelo Programa constatado entre os agentes educacionais e cursistas não impediu que fossem apontados diversos aspectos que merecem correções, ou são passíveis de melhoria.

\section{Os recursos da comunicação}

Na Europa a educação à distância desenvolveu-se em decorrência da evolução da pedagogia de sala de aula para a complementação do aprendizado regular e da profissionalização (Brasil 1994). No Brasil, diferentemente, apenas nos anos recentes essa tradição começa a delinear-se. O grande potencial dos meios de comunicação aplicados à educação ainda está para ser explorado entre nós, particularmente no domínio do ensino público, mas nessa direção o Programa "Um salto para o futuro" ousou avançar em relação ao que vem sendo experimentado na área.

Projetos de teleducação envolvem, de um lado, professores, especialistas e pedagogos e, de outro, o trabalho de profissionais de tele- 
visão, vídeo e jornalistas. Como lembra Magaldi (1987, p.15), esses grupos possuem culturas profissionais muito distintas umas das outras, nas quais predominam linguagens, habilidades, motivos, valores e visões de mundo diferentes. Para evitar a dissociação entre conteúdo e forma no processo de criação e de produção é preciso reconhecer a natureza e as especificidades da teleducação e assumir o fato de que esses dois grupos de profissionais devem trabalhar de modo integrado desde a concepção do programa até a sua última etapa.

No caso do "Um salto para o futuro" os recursos técnicos da televisão educativa da Rede Brasil que o produziu estão bastante aquém dos disponíveis no próprio país, tendo sido mantidos alguns padrões de composição e de montagem simples, menos onerosos. Embora o conteúdo dos vídeos e boletins deixe de usar plenamente as possibilidades oferecidas pela combinação dos meios de comunicação mais modernos como o fac-símile, o canal de voz e a televisão, e mesmo dos mais tradicionais como os textos, a estrutura formal dos programas televisivos da série consegue ser atraente e motivadora na opinião da maioria dos que tiveram contato com eles.

A colaboração de profissionais na produção dos programas de televisão amplia-se no caso em estudo, se considerarmos a participação dos professores presentes nas telessalas como um tipo de co-produção do texto televisivo. Esta precisa ser destacada na série, dentre outros motivos, pelo fato de que a parte interativa ocupa cerca de $52 \%$ do tempo da programação televisiva diária, de 33 minutos, que faz parte das atividades do curso.

O "Tira-dúvidas", como é chamado, é o momento do programa televisivo em que os cursistas fazem perguntas ao vivo aos especialistas, que lhes respondem no ato. Trata-se do momento por excelência da participação, da troca, da interação entre equipe de produção e telealuno, que permite a expressão das necessidades educacionais dos professores cursistas e oferece oportunidade aos especialistas de ajustarem a fala e as propostas, adequando-as à realidade; de trocarem em miúdos explicações muito teóricas e de chegarem mais perto da experiência vivida nas escolas. Os alunos, além de se sentirem partícipes, terminam por apreender uma visão nacional das questões em pauta, evidenciando seus aspectos comuns e especificidades, o que contribui para ampliar suas referências culturais e educacionais.

A interação é também assegurada por meio de um grande volume de perguntas e respostas trocadas via fax durante e depois do progra- 
ma televisivo. Nesse sentido torna-se importante explorar melhor as possibilidades do modelo interativo, que se mostrou, além do mais, grandemente motivador.

Como se trata de um programa de televisão, a busca de uma linguagem própria do veículo levou à concepção da programação diária como uma unidade discreta, com começo, meio e fim, que, em princípio, bastava-se a si mesma para ser entendida, sem necessariamente depender do que foi tratado nas programações anteriores ou do que seria abordado nas seguintes.

Para a equipe produtora certamente não deve ter sido tarefa fácil conciliar a opção por essa característica da programação diária com alguns dos pressupostos do currículo subjacente que informam o programa de capacitação: a continuidade, o aumento gradativo da complexidade e uma certa coesão entre os componentes. Não obstante, pode-se dizer que, salvo sob uns poucos aspectos, o trabalho foi bem-sucedido sob esse ponto de vista.

Uma das freqüentes sugestões quanto à abordagem substantiva do Programa é aquela que enfatiza a necessidade de buscar uma linguagem mais calcada nas experiências vividas nas salas de aula brasileiras no decorrer de toda a programação televisiva e não apenas nos momentos interativos. A partir daí, haveria que se explorar melhor os processos indutivos capazes de levar os professores-cursistas a um domínio maior dos conhecimentos e à reflexão sobre as práticas que se pretende que eles incorporem. A utilização de vídeos educativos do exterior não dispensa, por sua vez, um esforço de recontextualização que ainda não foi experimentado na abordagem das diferentes áreas.

Na perspectiva da produção do programa teleducativo, observase certa tendência a considerá-lo predominantemente como auto-suficiente, do mesmo modo que são concebidos os demais programas de televisão. Pouco se investiu em material de apoio pela iniciativa de seus produtores. Encontram-se nas indicações bibliográficas referências imprecisas, textos publicados no exterior, boletins amoldados exclusivamente ao formato da TV, sendo que a bibliografia referida foi inacessível à maioria absoluta dos cursistas.

Dentro de uma perspectiva educacional mais ampla, um programa de capacitação nacional de docentes deverá ultrapassar as limitações da televisão. Nesse sentido será preciso prover um acervo de material escrito de apoio, mais completo e aprofundado, ao qual os professores 
cursistas poderão recorrer à hora que quiserem e quantas vezes julgarem necessário, acervo esse que os estados poderão ampliar e enriquecer na medida de suas possibilidades, como já o vem fazendo em certa medida. Entretanto, textos considerados fundamentais não poderão deixar de estar presentes em cada estado, e deverão ser supridos, se necessário, pelo próprio MEC. Além disso também poderá ser programada uma forma mais intensiva de sua utilização, a começar pela iniciativa dos órgãos encarregados da execução do " Um salto para o futuro".

\section{O Programa em ação}

Na década de 1970, as justificativas para a introdução em maior escala da educação à distância nos sistemas de ensino pautavam-se no pressuposto de que era possível produzir bons cursos, com bom material, que atingissem rapidamente a milhares de pessoas, convidando os melhores técnicos para prepará-los. Essa estratégia de amplo alcance era pensada em função da escassez de professores e/ou do mau preparo dos existentes, e, em última instância, considerava a tecnologia do ensino como uma categoria à parte, capaz de por si mesma provocar grandes mudanças, substituindo os docentes (Hawkins 1995). Constatouse, porém, que os bons resultados obtidos nos moldes do ensino à distância estavam aliados à qualidade da monitoria prestada aos alunos, de sorte que não se tratava de dispensar os agentes humanos mas de apoiá-los nas suas tarefas educativas.

O Programa, que visa melhor preparar os docentes através do desenvolvimento da capacidade de reflexão crítica sobre a sua prática docente a partir dos conteúdos e orientações veiculados, não prescinde do apoio do orientador de aprendizagem através de discussão monitorada. Este vem sendo, no mais das vezes, um professor normalmente lotado em cargos técnicos de orientação pedagógica ou de supervisão nos sistemas estaduais de ensino, com formação de nível universitário.

Qualquer generalização acerca da qualidade da atuação desse profissional seria contudo temerária, assim como já assinalado em geral, dadas a extensão territorial do país e a diversidade de situações de implementação do Programa. Seu desempenho pode variar, como observado, mostrando-se desde o de mais excelente teor, capaz de agregar elementos novos e analisar as implicações teórico-práticas da propos- 
ta, até aquele que, por falta de uma formação mais sólida do orientador de aprendizagem, restringe-se a um tratamento aligeirado dos temas, extremamente formal e atrelado à formulação dos textos televisivos e dos boletins. Em vista da natureza do estudo, não houve condições de apurar o peso específico do papel do orientador de aprendizagem em relação ao aproveitamento geral dos cursistas.

Entretanto, a concepção aberta do curso tem permitido que em várias localidades se recorra à colaboração de especialistas, ligados às instituições de ensino superior, com vistas à elucidação e ao aprofundamento dos temas suscitados pelo Programa. Em outras realidades parece ocorrer também uma interessante colaboração de outros profissionais ligados às áreas sociais ou de produção, contribuindo para o desenvolvimento dos temas abordados durante o curso. Tanto em um como em outro caso essa colaboração pode vir a suprir deficiências dos orientadores de aprendizagem. Mas o sentido da sua colaboração é mais amplo, na medida em que favorece a articulação da proposta com outros setores que produzem ou detêm conhecimentos julgados relevantes, agregando competências locais ao esforço de requalificação docente.

As trocas de experiência são, mais do que em qualquer outra modalidade de capacitação, grandemente favorecidas no Programa. Após levar à sala de aula uma proposta veiculada no curso, o telealuno a retoma, discutindo com os colegas e o monitor nas telessalas os seus aspectos positivos e os eventuais impasses criados, as dúvidas e as indagações, o que estimula os demais a adotar procedimentos semelhantes. Há também uma disposição de ajuda mútua entre os cursistas, tanto em relação à formação individual, quanto à diversidade de tarefas. É freqüente que o professor cursista tenha interesse no que está sendo sugerido para outra série que não a sua, porque nunca tem certeza da série em que vai trabalhar no ano seguinte. Assim, como no dizer de Nóvoa, "a troca de experiências e a partilha de saberes consolidam espaços de formação mútua, nos quais cada professor é chamado a desempenhar, simultaneamente, o papel de formador e de formando" (1992, p. 26).

Essa oportunidade de compartilhar experiências entre os pares, de certo modo, neutraliza as dificuldades decorrentes do fato de que os professores dos telepostos provêm, via de regra, de várias escolas da localidade. O próprio Nóvoa tem alertado para o fato de que "a organização das escolas parece desencorajar um conhecimento partilhado dos professores, dificultando o investimento das experiências significativas 
nos percursos de formação e a sua formulação teórica" (1992, p. 26). Como sozinhos, ao regressarem à escola, os professores não costumam encontrar ambiente propício à inovação, o grupo do teleposto serve de estímulo recíproco àqueles que buscam mudar.

Existem porém variações na formação dos grupos de telealunos. No estado de Mato Grosso a escola inteira está envolvida no projeto de aperfeiçoamento docente, criando condições institucionais de atuação conjunta. As discussões continuam em hora atividade-remunerada no estabelecimento de ensino, o trabalho é desenvolvido com grupos formados por séries e está associado ao projeto de sistematização da reforma curricular desenvolvido pela Secretaria de Educação. Em outros estados têm sido encontrados cursos condensados em fins de semana, oferecidos a professores residentes em locais distantes e em zona rural. Por iniciativa própria ou dos órgãos encarregados da sua implementação, há lugares em que a programação é gravada em vídeo e posteriormente trabalhada pelas equipes das escolas. Há ainda considerável utilização do Programa em cursos de habilitação para o magistério.

De modo geral tem-se a impressão de que as técnicas de animação do trabalho em grupo ocupam grande espaço nas atividades com os telealunos e despertam muito interesse pelo curso. Dão mostras disso, não apenas evidências colhidas das observações nas telessalas, como também o fato de que há mais textos que circulam em alguns estados sobre o assunto do que os relativos ao desenvolvimento dos temas substantivos. Em que pesem os aspectos motivadores provocados por tais técnicas, quando se considera que o tratamento teórico-metodológico conferido às áreas de estudo é bastante complexo e novo para a maioria, não só dos cursistas como dos próprios agentes educacionais, o esperado seria que houvesse maior circulação dos subsídios relativos aos temas substantivos. Se, em certos casos, o interesse pela dinâmica de grupo está se sobrepondo ao interesse pelo aprofundamento do conteúdo, é provável que este não esteja sendo trabalhado apropriadamente.

Quanto aos conceitos básicos veiculados, verificou-se, através da análise dos questionários respondidos pelos alunos e da observação nos telepostos, que, de modo geral, foram apreendidos de forma razoavelmente satisfatória pelos cursistas, pelo menos no plano de sua verbalização. Cumprirá, em outra ocasião, ir além na avaliação do impacto do Programa, de modo a obter evidências sistematizadas de seus efeitos na esfera da prática docente, dos resultados refletidos no desempenho dos 
alunos e da persistência ou não de mudanças desejáveis eventualmente detectadas.

De um lado, o caráter atualizado, contemporâneo e, por vezes, profundamente inovador da proposta educacional veiculada pelo Programa em relação às práticas correntes no país é o seu ponto forte. De outro, contudo, essas mesmas características contribuem para evidenciar o seu lado frágil. Ainda que a duração da programação seja relativamente longa por se tratar de capacitação em serviço, esta, por si só, não tem condição de consolidar os novos caminhos em que inicia os professores. Fica patente o caráter introdutório do Programa, de sorte que ele não dispensa o aprofundamento dos novos conhecimentos e conceitos veiculados. Assim sendo, o programa de TV não substitui outras formas de capacitação utilizadas nos estados. Pode complementá-las, enriquecê-las, ou funcionar como ponto de partida para a renovação curricular em diferentes pontos do país. Mas é, certamente, só o começo.

O esperado também é que outros módulos, ou cursos do gênero, venham a ser produzidos, visando à continuidade e ao aprofundamento da proposta.

\section{A implementação}

A operacionalização das ações do MEC previa para 1992, entre outras, a capacitação através de meios convencionais e de educação à distância, de 1/3 dos docentes da rede pública do ensino fundamental, estimado em 300 mil professores. Para tanto, o investimento nessa área, considerada essencial em uma política de mudança de qualidade, foi priorizado em relação aos governos anteriores, tendo saltado de $4 \%$ para $20 \%$ dos recursos alocados (Brasil 1992a).

As competências em relação ao Programa foram estabelecidas nos termos que se seguem:

Cabe ao MEC/Seneb orientar e coordenar a política nacional de educação, prestar cooperação técnica e assistência financeira aos estados, viabilizar a presença das ações de teleducação nas unidades federadas e implantar um sistema de monitoria e avaliação do Programa. A Fundação Roquete Pinto fica incumbida de produzir e 
coordenar a veiculação do programa pela televisão educativa, coordenar a produção do material pedagógico complementar e implantar um sistema de acompanhamento da recepção nos telepostos.

Cabe às Secretarias de Educação inserir a programação no seu Plano Anual de Trabalho, o que implica esforço de captação de recursos no próprio estado. A incorporação das ações de educação à distância no plano de trabalho credencia, por sua vez, as Secretarias de Estado a receberem aporte técnico e financeiro do MEC. Cabe ainda às administrações estaduais a implantação da estrutura organizacional do Programa, a manutenção da infra-estrutura necessária ao funcionamento dos telepostos, a organização de um sistema de acompanhamento e avaliação do telecurso, bem como a certificação dos cursistas.(Brasil 1992b)

A despeito das atribuições formais de cada instância envolvida no Programa, verificou-se, na prática, uma certa margem de indefinição sobre o que compete a quem, particularmente no tocante à cobertura dos custos. Como para instalar e expandir o Programa o montante de gastos envolvidos é grande, o fato de que alguns estados já contavam com uma infra-estrutura montada pelo fato de terem desenvolvido outros programas teleducativos propiciou melhores condições de difusão da nova proposta em certos casos, como no Ceará e em Mato Grosso. No entanto, a distribuição de responsabilidades e encargos entre as instâncias federal, estadual e municipal, e particularmente em relação aos custos do Programa, tem-se revelado o seu calcanhar-de-Aquiles.

No primeiro semestre de 1992 a programação do curso parece ter contado, em certas unidades federadas, com incentivo do MEC na forma de ajuda de custos. Entretanto, isso não ocorreu, pelo menos na forma ou na proporção desejada no segundo semestre, o que provocou frustração dos agentes educacionais e dos cursistas, e, por vezes, a sensação por parte da coordenação, de que o estado estaria sendo lesado por arcar com mais do que foi combinado em termos de despesas.

Essa situação de grande dependência em relação ao MEC para a implementação do Programa não foi constatada contudo em alguns estados. Em Mato Grosso, observou-se um grande envolvimento da Secretaria Estadual de Educação com o Programa, e, mais do que isso, um esforço deliberado de encampá-lo e incorporá-lo às demais atividades voltadas para a capacitação docente, que incluem convênios com duas universidades brasileiras e uma no exterior para educação à distância. 
No outro extremo encontra-se o estado de São Paulo, o mais desenvolvido da Federação. Pelo fato de estar realizando um programa próprio de capacitação docente com dimensões inusitadas, que chegou a atingir cerca de 87 mil docentes em 1992, combinando a abordagem tradicional com novas tecnologias e envolvendo as universidades paulistas, a Secretaria da Educação deixou em segundo plano o Programa do MEC.

O estado do Ceará, por sua vez, optou por dirigir o Programa às numerosas escolas comunitárias aí existentes, porque estas não são assistidas por nenhuma outra forma de acompanhamento técnico. Outra opção tomada foi a de expandir a programação via municípios. Desse modo, os professores da rede estadual não estão sendo atingidos, dado que recebem outras modalidades de capacitação. Daí resulta a predominância de cursistas leigos no estado, sendo a regra, na capital, o trabalho voluntário não remunerado. Essa especificidade termina por contaminar, de certo modo, as ações do Programa, fazendo-o mover-se sobretudo em função da boa vontade e do esforço pessoal dos envolvidos, de forma pouco institucionalizada portanto.

Em alguns dos estados visitados, o apoio das Secretarias de Educação pareceu insuficiente para dar sustentação a contento às ações programadas.

A contribuição dos municípios para a expansão do Programa via de regra ainda tem sido bastante incipiente, sendo que nessa instância o nível de responsabilidade das diferentes esferas parece ainda menos claro. Há prefeituras que colaboram com o estado responsabilizando-se pelo transporte dos cursistas, notadamente nas áreas rurais; pela merenda, indispensável no caso daqueles grupos de professores que, após dobrarem a jornada de trabalho, prosseguem no curso praticamente sem interrupção; pela reprodução dos boletins, ainda que haja casos em que os materiais nem mesmo estejam sendo reproduzidos, pois "anos eleitorais exaurem os recursos dos municípios", como comentam agentes educacionais.

Uma outra modalidade de implementação do Programa tem sido feita através de universidades ou institutos isolados de ensino superior, embora ainda em proporções muito reduzidas. Em mais de um caso constatou-se que a iniciativa da criação de telepostos partiu do ensino superior ou a sua manutenção viabilizou-se através dele, embora nem sempre tenha sido observado um maior entrosamento dos professores universitários com a proposta. 
Quanto à abrangência, constatou-se que em 1992, primeiro ano de sua implantação, "Um salto para o futuro" atendeu 29.633 cursistas, tendo ampliado a cobertura para 26 unidades federadas, incluindo as capitais dos estados e alguns municípios do interior. Ora, quando se considera, de um lado, a meta proposta pelo MEC, de 300 mil pessoas a serem capacitadas, e, de outro, as potencialidades de multiplicação acenadas por programas de educação à distância, conclui-se que há ainda muito a caminhar na trajetória iniciada pelo Programa, mesmo considerando que existe ainda um público não quantificado que assiste espontaneamente ao curso. É preciso reconhecer ainda que muito do realizado até agora se deve ao empenho dos agentes educacionais envolvidos no Programa, mais do que a condições institucionais, senão ótimas, pelo menos mais propícias à sua consecução.

Aqui, tal como costuma acontecer em outros programas do gênero, a grande promessa de penetração que pode ter um programa transmitido via satélite como esse acaba se traduzindo mais uma vez em um pífio resultado. Em verdade a avaliação do impacto de uma iniciativa dessa natureza não estará completa se não se apurarem devidamente os custos de sua produção, instalação e implementação, via de regra altíssimos em iniciativas desse porte, sobretudo quando se considera o baixo retorno em relação à audiência alcançada. A metodologia utilizada neste estudo não permitiu aprofundar esse aspecto, mas as poucas indicações colhidas sugerem que, além dos custos de produção e de instalação da alta tecnologia demandada pelo Programa assumidos pelo governo federal, será preciso também estimar mais realisticamente os custos de implantação e implementação dos telecursos, que, parece, não foram devidamente equacionados em nenhuma instância no momento em que se concebeu e se quis colocar em prática essa modalidade de atuação.

Para ter abrangência significativa, a implantação e a manutenção de um programa desse porte implicarão dispêndios consideráveis por parte dos estados que, é fato sabido, têm os seus recursos comprometidos quase integralmente com as despesas de custeio das extensas redes de ensino por eles mantidas. Assim, mesmo sendo o Programa incorporado ao Plano de Trabalho Anual das Secretarias Estaduais de Educação, a disponibilidade de recursos financeiros para ele parece ser bastante reduzida, particularmente naqueles estados mais pobres, de economia menos dinâmica, como é o caso de muitos que dispõem de meios escassos para formar e reciclar os quadros do magistério. A despeito dessas limitações, a reprodução em vídeo do Programa em escala maior e acompanhada de um conjunto de materiais escri- 
tos subsidiários poderá igualmente aumentar de modo significativo as suas possibilidades de utilização pelas redes de ensino.

Se a opção do MEC for a de realmente apostar nas novas possibilidades de capacitação abertas por esta modalidade, terá que exercer mais fortemente a sua ação supletiva, especialmente do ponto de vista do apoio financeiro, de modo a viabilizar a expansão do Programa, notadamente nos estados do nordeste e do norte do país, regiões que, pelas maiores carências dos seus sistemas de ensino, são as que mais necessitam de apoio.

A descentralização decorrente da Constituição Federal de 1988 determinou, por sua vez, que um considerável montante de recursos arrecadados pelos municípios permaneça nas próprias localidades. Ora, naqueles de maior arrecadação, parcela maior desses recursos pode e deve ser carreada em maiores proporções para a melhoria do ensino fundamental. Assim sendo, um trabalho sistemático junto aos municípios com recursos humanos e materiais abundantes certamente poderá ampliar consideravelmente a capacidade de expansão do Programa através de ação conjunta. Além disso, se o remanejamento dos recursos públicos para o ensino fundamental através de um fundo comum vier a contemplar melhor a grande maioria de municípios onde tais recursos são reduzidos, as possibilidades de equacionar com mais autonomia o atendimento das necessidades de seu corpo docente aumentarão.

Do mesmo modo, um maior envolvimento com as instituições de ensino superior, hoje mais sensibilizadas para a necessidade de formação e reciclagem dos quadros do magistério do ensino fundamental, também poderá resultar em desdobramentos profícuos das ações previstas nessa direção.

E, finalmente, a participação de outras agências da sociedade civil, tais como entidades culturais, científicas, empresariais, sindicais, de moradores, também poderá contribuir para explorar melhor as inúmeras possibilidades colocadas por uma proposta aberta de capacitação docente como esta que vimos analisar.

\section{Considerações finais}

O Programa "Um salto para o futuro" representa, pois, uma combinação de recursos de televisão, fax, telefonia e material impresso que, sem 
dúvida, pode ser considerada um avanço em matéria de educação à distância no país. Além de se traduzir numa forma nova e participativa de veicular a mensagem que se propõe a passar, através de transmissão monitorada, representa uma proposta também inovadora do ponto de vista educacional no que se refere aos conteúdos e às orientações oferecidas aos professores das séries iniciais do ensino fundamental.

Há muito no Programa que pode ser melhorado tanto do ponto de vista do projeto educativo, quanto da exploração dos recursos técnicos, mas a sua concepção e a orientação básica que ele ensaiou parecem apontar para caminhos bem promissores.

Considera-se que ele poderá vir a constituir importante instrumento de atualização dos professores que participam do curso e conseqüentemente da prática educativa que desenvolvem em suas salas de aula. Poderá, ainda, atingir, indiretamente, um sem-número de instituições que oferecem cursos de formação para o magistério espalhadas pelo país, que tantas dificuldades encontram para se sintonizar com as orientações mais contemporâneas na área. Para tanto, será, porém, necessário melhor equacionar os custos requeridos para implementá-lo e ampliar os parceiros para expandi-lo.

Eis, portanto, uma boa proposta ainda em busca da sua realização plena!

\section{Multimedia training for primary teachers in Brazil}

ABSTRACT: This article is a reflection based on a national program of external evaluation of teacher training transmitted via satellite: "A leap for the future". It contains data from a field research including sample of T.V. classrooms in eight states from different regions of the country. It examines the program's theoretical and methodological proposals and format, as well as the interaction of educational agents, the advantages gained by teachers and finally conditions for implementing the program. The evaluation concludes that the program is innovative in its form and content, and could become an important vehicle for recycling primary teachers. However, it is insufficiently implemented. 


\section{Referências bibliográficas}

BARRETTO, Elba S. de S. (org.). "O Programa 'Um salto para o futuro', avaliação externa”. São Paulo, Fundação Carlos Chagas, 1993 (Relatório de Pesquisa).

BONAMINO, A.C. de e BRANDÃO, Z. "Currículo: Tensões e alternativas". Cadernos de Pesquisa no 92. São Paulo, Cortez, fev. 1995, pp. 16-25.

BRASIL. Ministério da Educação e Cultura. SEF. "Proposta de diretrizes de política para a educação à distância". Cadernos Educação Básica. Brasília, MEC/SEF/Codead, 1994 (Série Institucional 7).

SENEB. "Política de educação básica. Linhas de ação para 1992". Brasília, jan. 1992a.

SENEB. "Programa nacional de teleducação: Monitoria". Brasília, MEC/DEF/Codead, 1992b.

FUNDAÇÃO ROQUETE PINTO. "Um salto para o futuro". Rio de Janeiro, julho 1992 (Documento Básico).

FUNDAÇÃO ROQUETE PINTO. "Um salto para o futuro". Rio de Janeiro, ago. 1992 (Boletim Especial).

HAWKINS, J. "O uso de novas tecnologias na educação". Revista Tempo Brasileiro no 120. Rio de Janeiro, Tempo Brasileiro, 1995, pp. 57-69.

MAGALDI, S. "Televisão a serviço da educação". Rio de Janeiro, junho 1987, mimeo.

NÓVOA, A. "Formação de professores e profissão docente". In: Nóvoa, A. (org.). Os professores e a sua formação. Lisboa, Publicações Dom Quixote, 1992, pp. 15-33. 